\title{
Phonatory Vocal Tract Stability in Stuttering Children before and after Fluency - Enhancing Therapy
}

\author{
Dehqan $\mathrm{A}^{1}$, ali Dashti $\mathrm{G}^{2}$, Mirzadeh $\mathrm{M}^{3}$
}

\author{
1,2Department of Speech Therapy, \\ ${ }^{3}$ Computer software engineer, \\ Zahedan University of Medical Sciences, \\ Zahedan, Iran
}

\section{Corresponding Author}

Ali Dehqan

Department of Speech Therapy,

Zahedan University of Medical Sciences,

Zahedan, Iran

Email.dehqan@usa.com

Kathmandu Univ Med J 2010;9(32):405-9

\section{ABSTRACT \\ Background}

Stuttering is a complex disorder. Essentially, it is a neuromuscular disorder whose core consists of tiny lags and disruptions in the timing of the complicated movements required for speech.

\section{Objective}

The purpose of the current study was to collec and comparg jitters and shimmer values in children who stutter before and aftea fluency - enhancing therapy.

\section{Methods}

Subjects consisted of 15 Iranian preschool girls with stutterg, and 15 Iranial preschool girls without afflictions, matched according to age. Vocal jittering and shimmer measurements of thesphonation of the children were compared before and after therapy. Each subject phonated vowels nine times in a random order. Each phonation was sustained for at least five seconds and was recorded. The middle three-second portion of each recorded vowel phonation was subjected to jitter and shimmer analysis.

\section{Results}

On shimmer measures between pre-treatment and post treatment, significant differences were found in all sustained vowels of persons who stutter group and means of shimmer in post therapy were significantly lower than pre-treatment. Differences in jitter measurements were not significant between pre-treatment and post-treatment statuses and this parameter did not change after therapy.

\section{Conclusion}

The findings showed that therapy resulted in decreaseg irregularity in the amplitude of vibrations (shimmer). In other words, the therapy increases the steady-state of the laryngeal system. Moreover, this parameter may be used as an index for the effectiveness of therapy.

\section{Key Words}

children, jitter, phonation, shimmer, stuttering, voice 


\section{INTRODUCTION}

Stuttering is a complex disorder and essentially it is a neuromuscular disorder whose core consists of tiny lags and disruptions in the timing of the complicated movementsrequiredforspeech. ${ }^{1,2} \mathrm{Obvious}$ disturbances inthespeechproductionsystemofstutteringindividuals mightberelatedtogeneralizedtemporalincoordination between respiration, phonation and articulation. ${ }^{3}$

Alargebodyofliteraturehasaccumulatedinsupportofthis viewthatindividualswhostutter, differfromindividuals whodonotstutterinatleastsomeoftheneuromuscular processes involved in speech production. ${ }^{4-8}$ Several authorshaveproposedincoordination oftheseactionsasa specificversionofthegeneralhypothesisthatstutteringis a disorder of timing. ${ }^{9,10-15}$

One of the most important factors that predict high precisiontemporalcoordinationisphonatoryvocaltract stability. Vocal perturbation measures are short-term indices ofthestability ofthephonatorysystemand both may be associated with poor laryngeal control. ${ }^{3}$

Irregularityofthefundamentalfrequencyoroftheperiod ofsubsequentglottalcyclesiscalledjittering.Shimmeris duetotheoverlappingofthefundamentalfrequencyofthe voicewithanoisewhichleadstoamplitudeirregularities. ${ }^{16}$

Severalstudiesthatexaminedspeechacousticsofpersons who stutter (PWS) and Persons who do not stutter (PWDS) have found that PWS, as a group, show longer voice onset times (VOTs), vowel durations, stop gap durations,andconsonant-voweltransitiondurations. ${ }^{17}$ Baer (1979)considered thatstuttering childrenhaveweaker laryngealneuromuscularcontrolandgreaterdisturbances in integrating respiratory and laryngeal control which justifies measurements of voice disturbances. ${ }^{18}$ On the otherhand,fewstudies haveexamined thedifferences invocaltractstabilityduringspeech productionbetwer (WS) ar (PDS). Klich and May (1982) suggested that thestuttererswereproducingvowelsusinganeutralvocal tract posture as a means of controlling speech fluency. ${ }^{19}$ Mostresearchershaveexaminedthepossibledifferences inoral-laryngealcoordinationbetweenstutteringandnonstutteringindividuals.PesákandUrbánek(1993)studied incoordination ofthephonationstartinindividualswith stuttering and found that in the group of children and adolescentswithstutteringonlylessthan $4 \%$ ofthecases showedundisturbedregularphonationstarts, whereasin thecontrolgroupitwasalmostasmuchas 90 percent. ${ }^{20}$ Falck,LawlerandYonovitz,(1985)found thatadultswho stutteredexhibitedmeasurablecycle-to-cycletemporal changespriortomomentsofstuttering. ${ }^{21}$ Suchchanges were absent in the identical but fluent utterances of the same speaker. Newman, Harris and Hilton (1989) found that PWS as a group showed higher amplitude irregularities during sustained vowel productions and their findings showed differences between stutterers and non-stutterers in the laryngeal behavior (i.e., $F_{0}$ perturbation).Thisfindingwasinterpretedasmaintaining a fixed laryngeal posture during vowel steady-state production. ${ }^{22}$ Bamberg,Hanley, and Hillenbrand(1990) alsoreportedsignificantlyhighervocalshimmervaluesin thefluentspeechofPWSthantheirfluentpeers. Halland Yairi(1992) examinedacousticcorrelates of phonatory controlinthespeechof10preschool-agedboyswhowere stutterers and in the speech of 10 boys who were nonstutterers.Significantdifferenceswerefoundbetweenthe twogroupsforshimmermeasures. ${ }^{3}$ Robb,Blomgrenand Chen(1998)found thatPWSenrolledinfluency-shaping therapydisplayedtheleastformantfrequencyfluctuation (FFF) (most vocal tractstability) and the untreated PWS displayed the mostFFF (leaststability). ${ }^{23}$ Salihovićetal. (2009) compared the speech of 67 children whostutter with thespeech of 46 fluentspeakersandconcludedthat thereweresignificantdifferencesbetweenthetwogroups for jitter and shimmer measures. ${ }^{24}$

Unfortunately,researchaddressinglaryngealfunctioning inpeoplewhostutterhasbeenprimarilyfocusedonadults. Whenchildrenmature,theyexhibitagreatercontrolover laryngealadjustmentsthatisreflectedintheincreasing stabilityofvocalfoldvibration. ${ }^{3}$ Similarly, datashowsthat vocal jitter and shimmerdecreases a lg with age, , as it is interpreted tohaving greatercntrol. ${ }^{25} \mathrm{ALlowerindices}$ of magnitudeoneitherjitterorshimmerindicatelessvocal perturbationandgreaterstabilityinthefinemotorcontrol of phonatorehavior.IfShould themagnitude ofvocaer orshimmer, in thefluent phonatorybehaviours ofPWS (eitherjitteshimer)wasshowntobesignificantlygreater than of PWNS, this it would provide additional support tothehypothesisthatPWSmaydemonstrategenerally lesscompetentneurophysiologicregulation. ${ }^{22}$ Moreover, researchhasnotdocumented theacousticmeasures of jitter,orshimmerinthephonationsofyoung childrenin pre-theapyandpost-therapy.Dataonthevariousaspects oflaryngealfunctioninchildrenwhostuttermayenhance theunderstanding ofthedisorderwithinthecontextof developmental processes of the speech., 22

Thecurrentstudywas designed togatherandcompare the jitter and shimmer values of PWS in two different conditions(i.e.pre-theapyand pforobtaininginorderto gainabetterundersingaboutthephonatorymotorcPWS population.Theresultsthisstudyltcanbeusedinfuture therapysses and used as an index of the progression of therapy. 


\section{METHODS}

Subjects: Subjected of fifteen 15 ss and ffteen 15 nonstutterers matched according to age and sex. The age rangeofthestuttererswasfrom67to79monthsnd ofthe ntuttererswasrangedfrom66to79monthswithamean age of 72.6 for both groups. All subjects werefemale.

The Study design was a quasi-experithat was done conducted at the rehabilitation clinic of Zahedan University ofMedicalwas8months.studywascarriedout over eight months,

Severalcriteriawereemployedforsubjectclassification.to beregardedwereobservedbybothparentsandtwospeech therapistsasexhibitingastuttering problemand hadto demonstrateatleastsixstuttering-likebehaviours(SLDs) ${ }^{3}$ per 100 wordsduringa300-wordsampleofconversation withtheirmothers, and/orifpeopleintheirenvironments hadexpressedconcernregardingtheirspeechfluency. ${ }^{26}$

The presence and magnitude of stuttering at the time of testing was verified using the Stuttering Severity Instrument. ${ }^{27}$ All were moderate level in SSI-3 Scale. Allsubjectswereperceptuallyassessedfornormality of their voices with the GRBAS scale, By means of sound reproduction ofeachvocalsample,thefollowingitems weregradedconjunctlybytwoprofessionalsexperiencedin vocal pathology, from0to3 using theGRBASmethod;(0 =normal, $1=$ slight, $2=$ moderate, $3=$ severe): $\mathrm{G}$ (Grade), the global grade of vocal affliction. R (Roughness), the quality of thevoicerelated totheimpressionofirregular glotticpulsesfromanoisecomponentoflowfrequency, of roughnessorvocalfry. B(Breathiness), thevoicerelated tothenoisethatoriginateswith theturbulencecreated by an incompetent glottis. A (Asthenia), the auditory impressionfweaknessinspontaneousphonation. Hypo kineticorhypofunctionalvoice.S(Strain,vocaltension), theauditoryimpression ofexcessiveeffortandoftension associated with spontaneous phonation. ${ }^{28}$ Those with ratingshigherthan 0 ,evenifitwasononemeasure, were excluded.Therating wasperformedonavoicesampleof one 1 minuteofspontaneousspeech.Subjectswerealso screenedonformerproblemswithbreathing,theirvoice, neurological diseases, and structural abnormalities in the larynx, mouth, or throat with a questionnaire. The second author checked their vocal folds with a flexible laryngoscopetoconfirmthatnoonehadorganiclesions of the vocal folds.

Theacousticexaminationwasperformedinasoundproof room with the subjects in a sitting position. Subjects attendedfluencyreinforcementpluscorrectivefeedback. The criterion of treatment success was less than $2 \%$ stuttering rate in all stages. ${ }^{29}$ The number of sessions of therapy depended on the individual child and varied
from26-90hours.Datacollectionwasperformedbefore starting treatment protocols, using the Dr. Speech 4.0 software(subprogramme:vocalassessmentversion 4.0 fromTigerElectronics,USA)atthespeechtherapyclinic. Themicrophone(type:ECM-717condensermicrophone, SonyCorporation)wasplacedoastandatom thefrontof mouth.Thesamesampleswererecordedaftertermination of terapy.

VoicesSamplestakenconsistedofthefivesustainedvowels of the Persian language, /â/, /a/, /e/, /o/ and /u/ in a comfortableandhabitualway,andeachsubjectphonated vowelsninetimesinrandomorder.Eachphonationwas sustainedforatleastfivesecondsand wasrecorded.The mid-3-second portion ofeachrecordedvowelphonation was subjected to jitter and shimmer analyzes.

Statisticsdatawereanalyzed withthestatisticssoftware SPSS 18.0 for Windows and data were subjected to a two-way analysis of variances (ANOVA) with repeated measures.

\section{RESULTS}

Means and standard deviations of jitter of PWS and normalpeershowedintheTtable1 and2forpre-treament and post-treatment statuses. On the jitter measures in pre-treatment and post-treatment conditions of both groupstherewerenotsignificantdifferences.Meansand standarddeviationsofshimmerofPWSandnormalpeers werpresentedint4, respectively.Onshimmermeasures betweenpre-andpost-treatment,significantdifferences were found in all sustained vowels of PWS group and means of shimmer in post- therapy were significantly lowerthanpre-treatment(p5).AsnotedicedinTtablere wasnotanysignificantdifferenceonshimmermeasuresin control group.

\section{DISCUSSION}

Asignificantdifferencewasfoundbetweenpre-treament and post-treatment statuses on measures of shimmer. However,thedifferencesofnjitterbetweenthetwostatuses werenottobestatisticallysinificant.TheMmeansfshimmer inofallofthevowelsinpre-treatmenstatuseswereasarger thanthoesemeauresdinpost-treatmentstatus,indicating thatthesustainedphonationsofthepre-treatmentwas lessstablethanthosethepost-treatmentintermofvocal intensity.Ontheotherhand,forshimmermeasures, there wasnotanysignificantdifferenceinthecontrolgroupthat wecanconcludethechangesinthemeasuresofsimmer in post-treatmentstatusresultsfromtherapyanditisnot dependtogrowing.Althoughthespecificneuromuscular components of vocaljitterand shimmerhavenotbeen 
identified,itispossiblethatshimmectsthegreaterficulty of with integrating respiratory, laryngeal, and cortical controlthanjitter. ${ }^{3}$ Although, itisdifficulttocompareour acousticdatawiththefindingsofotherstudiesbecausepast variousresearcheshasusedthevarietyofmethodologies that it limits comparisons across studies. However, it is interestingtonotesimilaritiesbetweenthepresentresults andacousticdatafrom literatureforchildrenandadults whostutter. ${ }^{3,22,24}$ The direction of ourfinding differenes wereobtained, suggest that stutterers haveless stable neuromuscular control over the events regulating the aerodynamics of the laryngeal and respiratory system duringsustainedfluentvowelarticulationsandfluency therapyincreasesteady-stateinlaryngealandrespiratory systemandledtodecreaseirregularityintheamplitude of vibration (i.e. shimmer). The steady state, sustained phonationinvolvesanevenmaintenanceofsuchforcesas vocalfoldtension, mass, length, and subgloticpressures, while it also maintains the supralaryngeal articulatory adjustmentsrequiredforproductionofthevowel.Onthe otherhand, itwasdeterminedthatstutteringindividuals havevariable,sometimesevenchaoticsubglotalpressure. ${ }^{30}$ Itisthoughtthatthisiscausedbymuscularincoordination ofthertact. ${ }^{31}$ However,Ddifferenceshavebeenobserved, however, betweenthetwostatuseswhichsuggest that childrenarebetterabletocontrol theseforces afterthe termination oftment.Therefoonthebasisofthecurrent studyfindings,measurementsofamplitudeperturbation ofvoicesuchasformantfrequencyfluctuationmeasures canbeusedasanindexofvocalttstability, astheithasalso beenusediresearchesut. ${ }^{23,32,33} \mathrm{Also}$, Thestudy willalso it canhelpclinicianstopursuetheprocessoftherapyandcan thenbeusedasanindexofeffecnarrowagerange; Itmust beacknowledgedthatthestudyhaspresentedwithcertain limitations,suchasthenumberofparticipantswhichwere used,andthenarrowagegroup, thus, itisrecommended thatthisstudybereplicatetherlargerorwidealargeranage rangesamplesofstutteringspeakers. stutteringadults.

\section{CONCLUSION}

Thefindingsfrom the presentstudy showed that there aren'tsignificantdifferencesonjittermeasuresbetween pre-reatmentand post-treatmentconditionsbutonthe otherhand, therearesignificantdifferencesonshimmer measuresbetweenpre-reatmentandpost-treetconditions. So, tThe latter parameter or shimmer has an important roleinthetherapeuticyprocessandcanbeusedasanindex of progression of therapy.

\section{REFERENCES}

1. SmithA.Stuttering:Aunifiedapproachtoamultifactorial, dynamic, disorder. In: Ratner NB, Healey EC, editors. Stutteringresearchand practice:Bridgingthegap.Mahwah, NJ:Lawrence Erlbaum;1999.p.27-45.

2. Maassen $B$,Kent $R$, Peters $H$, Van Lieshout $P$, Hulstijn W. Speech Motor Control in Normal and Disordered Speech.3thEd, New York,NY:Oxford University Press;2004.p.313.

3. HallKD,YairiE.Fundamentalfrequency,jitter,andshimmer inpreschoolerswhostutter.JSpeechHearRes1992;35:10028.

4. Alfonso,PJ.Implicationsoftheconceptsunderlyingtaskdynamic modeling on kinematic studies of stuttering. In Peters HFM, Hulstijn W, and Starkweather CWeditors, Speechmotorcontrolandstuttering,Amsterdam:Elsevier; 1991.p.79-100.

5. Caruso AJ, Abbs JH, Gracco VL. Kinematic analysis of multiplemovementcoordinationduringspeechinstutterers. Brain 1988;111:439-56.

6. Caruso AJ, Max, L, McClowry, MT. Perspectives on stutteringasamotorspeechdisorder.InCarusoAJ,Strand EA(Eds.),Clinicalmanagementofmotorspeechdisorders in children.New York:Thieme;1999.p.319-44.

7. Smith A, LuscheiE, DennyM,WoodJ,HiranoM,BadylakS. Spectralanalysesofactivityoflaryngealandorofacialmuscles instutterers.JNeurolNeurosurgPsychiatry1993;56:1303-11.

8. ZimmermannG.Articulatorydynamicsoffluentutterances of stutterers and nonstutterers. J Speech Hear Res 1980; 23:95-107.

9. Max L, Gracco VL. Coordination of oral and laryngeal movementsintheperceptuallyfluentspeechofadultswho stutter. J Speech Lang Hear Res 2005;48:524-42.

10. Adams MR. A perspective on stuttering. Contemplssues Commun Sci Disord.1999;26:5-13.

11. BoutsenF.Acomparativestudyofstresstimingofstutterers and nonstutterers. J Fluency Disord 1995; 20:145-56.

12. ContureEG,SchwartzHD,BrewerDW.Laryngealbehavior during stuttering: a further study. J Speech Hear Res 1985;28:233-40.

13. Perkins W, Rudas J, Johnson L, Bell J. Stuttering: discoordination of phonation with articulation and respiration. J Speech Hear Res 1976;19:509-22.

14. St.LouisK.Linguisticandmotoraspectsofstuttering.InN. Lass(Ed.),Speechandlanguage:Advancesinbasicresearch and practice .New York:Academic Press;1979.

15. Van RiperC.Thenature of stuttering.2nded.Englewood Cliffs, NJ: Prentice-Hall;1982. 
16. Colton RH, Casper JK, Leonard R. Understanding Voice Problems: A Physiological Perspective for Diagnosis and Treatment. Philadelphia, PA:Lippincott Williams \& Wilkins;2006.

17. BloodsteinO.AHandbookonStuttering.5thed.SanDiego, CA: Singular Publishing; 1995.

18. Baer T. Vocal jitter: A neuromuscular Explanation. In LawrenceV, Weinberg B editors, Care of the professional voice:physicalfactorsinvoice, vibratoregisters. NewYork: The Voice foundation;1979.

19. Blomgren $M$, RobbM,ChenY.Anoteonvowelcentralization instutteringandnonstutteringindividuals.JSpeechLang Hear Res 1998;41:1042-51.

20. Pesak J, Urbanek K. Incoordination of the phonation start in individuals with balbuties. Folia Phoniatr (Basel) 1993;45:62-7.

21. Falck FJ, Lawler PS, Yonovitz A. Effects of stuttering on fundamentalfrequency.JFluencyDisord 1985;10:123-35.

22. Newman P, Harris R, Hilton L. Vocal jitter and shimmer in stuttering. J Fluency Disord 1989;14:87-95.

23. Robb M, Blomgren $M$, Chen Y. Formant frequency fluctuationinstutteringandnonstutteringadults.JFluency Disord 1998;23:73-84.

24. SalihovićN,Junuzović-žunićL, IbrahimagićA,BeganovićL. Characteristic ofvoiceinstuttering children.ActaMedSal 2009;38:67-75.
25. Glaze LE, Bless DM, Milenkovic P, Susser R. Acoustic characteristic of children's voice. J Voice 1988;2:312-9.

26. DehqanA,BakhtiarM,PanahiSS,AshayeriH.Relationship betweenstutteringseverityinchildrenand theirmothers speaking rate. Sao Paulo Med J 2008;126:29-33.

27. Riley,G.D.StutteringSeverityInstrumentforChildrenand Adults. (3rd ed.). Austin TX: PRO-ED;1994.

28. Hirano M. Clinical Examination of Voice. New York: Springer-Verlag;1981.p.83-4.

29. HegdeMN.Treatmentprotocolsforstuttering.SanDiego, CA:Plural Publishing;2007.

30. Zocchi L, Estenne M, Johnston S, Del Ferro L, Ward ME, 18. Macklem PT. Respiratory muscle incoordination in stuttering speech. Am Rev Respir Dis 1990;141:1510-5.

31. Williams DF, Brutten GJ. Physiologic and aerodynamic eventspriortothespeechofstutterersandnonstutterers.J Fluency Disord 1994;19:83-111.

32. Gerratt BR. Formant frequency fluctuation as an index of motorsteadinessinthevocaltract.JSpeechHearRes 1983; 26:297-304.

33. ZwirnerP,Barnes GJ.Vocal tract steadiness: a measure of phonatoryandupperairwaymotorcontrolduringphonation in dysarthria. J Speech Hear Res 1992;35:761-8. 